Article

\title{
Life Cycle Cost Evaluation of Noise and Vibration Control Methods at Urban Railway Turnouts
}

\author{
Rodrigo Tavares de Freitas ${ }^{1}$ and Sakdirat Kaewunruen ${ }^{2, *}$ \\ 1 Department of Civil Engineering, University of São Paulo, São Carlos (11) 999737902 1, Brazil; \\ ro.tavaresf@gmail.com \\ 2 Department of Civil Engineering, School of Engineering, University of Birmingham, \\ Birmingham B15 2TT, UK \\ * Correspondence: s.kaewunruen@bham.ac.uk
}

Academic Editor: Yu-Pin Lin

Received: 29 August 2016; Accepted: 25 November 2016; Published: 3 December 2016

\begin{abstract}
A focus of the railway industry over the past decades has been to research, find and develop methods to mitigate noise and vibration resulting from wheel/rail contact along track infrastructure. This resulted in a wide range of abatement measures that are available for today's engineers. The suitability of each method must be analysed through budget and timeframe limitations, which includes building, maintenance and inspection costs and time allocation, while also aiming at delivering other benefits, such as environmental impact and durability of infrastructure. There are several situations that need noise and vibration mitigation methods, but each design allocates different priorities on a case-by-case basis. Traditionally, the disturbance caused by railways to the community are generated by wheel/rail contact sound radiation that is expressed in different ways, depending on the movement of the rolling stock and track alignment, such as rolling noise, impact noise and curve noise. More specifically, in special trackworks such as turnouts (or called "switches and crossings"), there are two types of noise that can often be observed: impact noise and screeching noise. With respect to the screeching (or flanging), its mitigation methods are usually associated with curve lubrications. In contrast, the impact noise emerges from the sound made by the rolling stock moving through joints and discontinuities (i.e., gaps), resulting in various noise abatement features to minimise such noise impact. Life cycle analysis is therefore vital for cost efficiency benchmarking of the mitigation methods. The evaluation is based on available data from open literature and the total costs were estimated from valid industry reports to maintain coherency. A 50-year period for a life cycle analysis is chosen for this study. As for the general parameters, an area with a high density of people is considered to estimate the values for a community with very strict limits for noise and vibration.
\end{abstract}

Keywords: railway noise; vibration; screeching noise; flanging noise; impact noise; abatement; mitigation; life cycle analysis

\section{Introduction}

In previous years, the railway industry has spent special attention towards urban issues with respect to such environmental impacts as noises and vibration, wastes, air pollution along the rail corridor, etc. It has developed various methods to mitigate noise and vibration resulting from wheel/rail contact along track infrastructure. This has resulted in a wide range of abatement measures that are available for the professionals of the industry today. Although there are many options in the market, their practical implementations depend upon general and physical constraints that affect the feasibility of most technological applications in the fields. The progression of these technologies have enabled the choices of more adequate methods for each best case scenario, but further studies ought to 
be carried out in order to properly assess if each one is fit for their purposes and suitable for the local environment. In practice, every solution must be analyzed through budget and timeframe limitations, which includes construction, maintenance and inspection costs and time allocation, while also aiming to meet other values, such as environmental impact, damage and wear to the whole infrastructure [1].

There are several cases and circumstances in a railway project design that requires noise and vibration mitigation methods and each circumstance is given different priorities for consideration. Traditionally, the audible disturbance caused by railways to the community are generated by wheel/rail contact sound radiation that can be expressed in different ways, depending on the movement of the rolling stock and track alignment, such as rolling noise, impact noise and curve noise. More specifically, the emphasis of this study is placed on the special trackworks such as turnouts. There exist two types of noise that should be evaluated at a railway turnout: impact noise and screeching noise (sometimes called "flanging noise"). With respect to the flanging noise, its mitigation methods are associated with curve lubrication technology in turnouts and crossings. The impact noise on the other hand emerges from the source made by the rolling stock moving through joints and discontinuities (i.e., transferring gaps) over the crossing zone of the turnout.

From the broad spectrum of methodologies to mitigate nuisance sounds, from rolling stock to infrastructure measures already put in practice in the railway industry, some already stand out due to this previous experience. For railway impact noises, jointless switches and swingnose crossings are the most recommended. As for curve noises in these components, such as squeal and screeching, rail friction modifiers, flange lubrication and wheel dampers happen to be the mostly commonly used. Recent studies show that mitigation methods are more efficient if aimed to the noise source, i.e., the wheel/rail contact interface mostly, rather than having specific infrastructure for it (see Table 1). Still, special bogie design presents significant results in the general abatement of noise generation.

Table 1. Reduction of wheel maintenance due to lubrication [2].

\begin{tabular}{cccc}
\hline Track/Vehicle Condition & Wheel Life (in km) & Wheel Life (in week) & Annual Wheel Cost (in $£$ ) \\
\hline No lubrication & 170,000 & 20 & 1.6 millions \\
Rail lubrication & 300,000 & 35 & 825,000 \\
\hline
\end{tabular}

As nuisance sounds are considered environmental impacts, which can cause hearing damage if their levels are high enough or disrupt daily activities and living conditions even if low, their tolerance by the neighborhood and overall communities varies from site to site [3,4]. Engineers and managers involved in the railway industry often receive noise complaints all around urban areas, and, to avoid such, there are limits already established in order to give a standard level of comfort for the stakeholders, independent of people's complaints. In addition, having a manageable noise and vibration abatement methodology indirectly impairs avoidance of other maintenance related problems that are as critical as noise and vibration. In many countries, such as in Europe, noise mitigation action is often required [5]. Thus, railway track maintenance and sound related mediation can be correlated as two parts of the same condition, and fixing or repairing one can affect the other. The effects of structural vibration can result in rapid track degradation, ballast pulverization and track settlements, alongside ballast dilation at turnouts and crossings, which can, on the other hand, all deteriorate the level of railway noises if not solved.

Therefore, to properly assess how to conduct assets' life cycles involved in the objective of this study and to develop a life cycle cost evaluation, a cross-cutting analysis ought to be made, considering the measures and its effects on maintenance and railway operators' finances. The aim of this paper is to evaluate life cycle costs of noise mitigation methodologies currently in place for railway turnout systems. Thus, this work will rely on a thorough study which starts from understanding the facilities, i.e., the special trackworks involved, and its noise related problems, finishing with their economic impacts based on a life cycle costing analysis with regards to extreme weather condition investigations. The methods for noise and vibration control at railway turnouts (switches and crossings) 
are highlighted in this paper, and their effects on the maintenance cost of the whole special trackwork components are evaluated. Moreover, the life cycle costs are presented through analysis against industry reports and past study review, which allowed a cross-cutting economic analysis of the methods for implementation, operation and maintenance.

\section{Noise Problems at Railway Turnout Systems}

\subsection{Turnouts and Crossings}

This study pays special attention to the special trackwork systems that are essential components in railway infrastructure, since they provide flexibility to traffic operation. It is important to note that switches and crossings, which, according to maintenance databases, stand for one of the major causes of track failures and defects (which can potentially lead to train derailments), requiring high maintenance costs [6]. Hence, this topic will describe its components and its effects on railway noise generation sources, as well as its impacts on life cycle costs.

Turnouts are generally comprised of a switch panel and a crossing panel, connected by a closure panel in between. As part of each of these panels, minor components are assembled for the entire turnout system, and each of them can be seen in Figure 1. Because of its complexity, the interactions between the wheel and the rail in these elements are the principal issue in the design and maintenance of railway systems, and thus these are among the most sensitive parts of the railway systems. Over time, the wheel/rail contact changes along the turnout, transferring the interaction from the stock rail to the switch rail, and, finally, to the crossing nose through the closure rails. Due to the high level of interaction and quantity of components, these special trackworks are involved in noise propagation in railways [7]. Particularly, the type of noise involved in these elements are often the impact noises generated from the crossing transfer zone and also the screeching noise, which will be further explained in the next section of this paper.

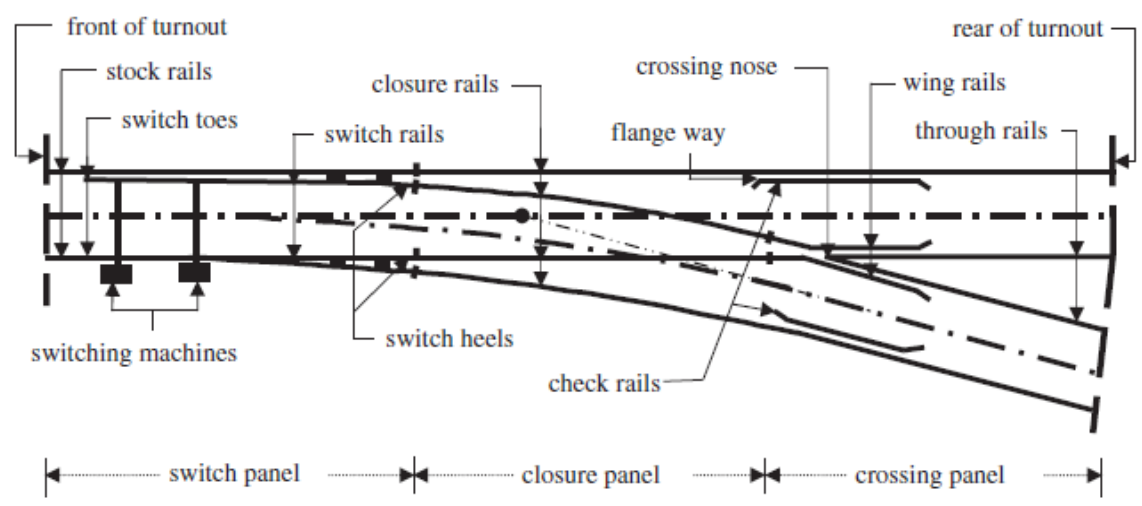

Figure 1. Components of a turnout [5].

\subsection{Noise Related Problems}

In railway systems, wheel/rail interaction is, in most cases, the primary source of noise and vibration. The ones generated by this interaction are generally categorized as squeal, impact or rolling noise [8]. Each of these has their particularities, which occur depending on different causes and produce different effects on railway tracks and other infrastructures. Squeals or screeching noise relates to the intense noise, occurring with one or more tones, generated when a vehicle travels around the curves of small radii [8]. When the rolling stock enters a curve, its wheels cannot keep their symmetrical, tangential direction since the axles are strict in the railway alignment and track geometry. Thus, the intense contact patch produces the squeal noise along the curve. The impact noise, on the other hand, is a term that describes the banging noise due to several situations, such as coupling and decoupling vehicles and marshalling yards, discontinuities in the rail or flat spots on the wheels. 
The sound generated is therefore due to a quick change in the dynamics of the wheel/rail interaction related to its vertical velocity, and this results in a large force at the interface that causes vibration and irradiate sound [9-14].

Finally, roar or rolling noise is one that is always present in railways since it derives from a dynamic rolling effect due to basic friction between rail and wheel, and due to roughness on wheels and rails.

In summary, to reduce each of these types of noises, some action plans have been recommended, as noted by [8-14]:

Squeal noise

- Reduce lateral creep during curve negotiation;

- Alter friction-creep characteristics at wheel/rail interface;

- Minimize resonant wheel response;

- Block sound radiation;

Impact and rolling noise

- Minimize wheel tread and rail surface discontinuities and roughness;

- Prevent wheel tread discontinuities;

- Minimize wheel/rail response to surface irregularities;

- Block sound radiation.

\section{Mitigation Methodologies}

\subsection{Mitigation Measures}

The most general approach to noise and vibration control is reducing and limiting the generated noise by targeting their principal cause (or at source). In special trackworks, as the wheel passes through switches and its other components, it encounters gaps that provoke, as a majority, impact noises, and also squeal (or screeching, in the case of turnouts and crossovers) due to the small curves that compose these elements [15]. To prevent or mitigate this nuisance source, a plethora of methods is available, which are listed below:

- Jointless switches;

- Resilient wheels;

- Noise barriers;

- Vehicle skirts;

- Rail grinding;

- Top of rail friction modifier-lubrication;

- Wheel damping;

- Welded rail.

The following sections will give a broader understanding of some of these methods that can then be evaluated through a life cycle cost analysis in Section 5.

\subsubsection{Resilient Wheels and Wheel Damping}

Resilient wheels are an all-around mitigation measure that reduces most types of noise generation. These kinds of wheels are structurally different than the regular ones by having the metal tire isolated from the wheel hub by an elastomeric material (see Figure 2). Figure 3 shows examples of rail damping. This not only reduces rolling and squeal noises by reducing the vibration of wheels, but also recent studies on these types of wheel show that impact forces are lowered by up to $40 \%$ [7-9]. 

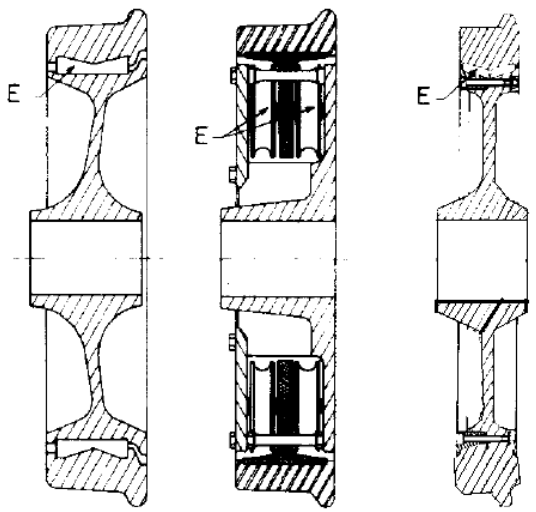

Figure 2. Various resilient wheels. E stands for the location of the elastomeric damping material [8].

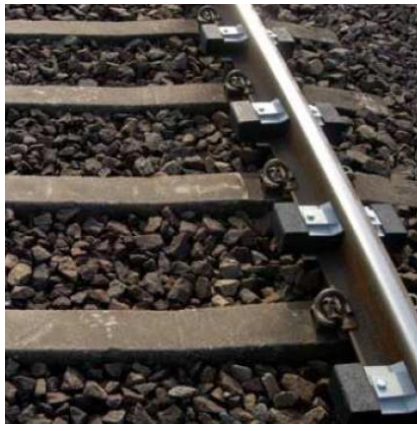

(a)

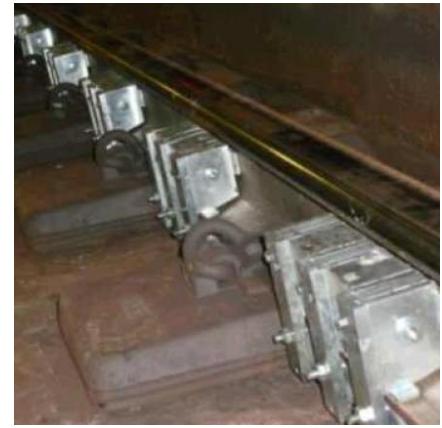

(b)

Figure 3. Examples of rail damping systems [2].

Apart from this, even though wheel/rail damping is a specific measure for rolling noise, their use showed promising results (see Table 2) for reducing impact and squeal noise. The principle of the damping system is that it abates the vibration waves along the rail and hence reduces the noise emitted.

Table 2. Noise mitigation measures reduction values [2].

\begin{tabular}{|c|c|c|c|}
\hline \multirow{2}{*}{ Treatment } & \multicolumn{3}{|c|}{ Wayside Noise Reduction, dB(A) } \\
\hline & Squeal & Impact & Roar (Rolling) \\
\hline Resilient Wheels & Reduces or eliminates & 0 to 2 & 0 to 2 \\
\hline Damped Wheels & Reduces or eliminates & 0 to 6 & 0 to 6 \\
\hline Resilient Treaded Wheels & $\begin{array}{l}\text { Undetermined (thin-tread) } \\
\text { Eliminates (Nitinol-tread) }\end{array}$ & 5 to 10 & 5 to 10 \\
\hline Wheel Truing & 2 to 5 & Eliminates flats & 2 to 6 \\
\hline Rail Grinding & 0 (Unpredictable) & 1 to 3 (joints and welds) & $\begin{array}{l}2 \text { to } 9 \text { Uncorrugated rail } \\
8 \text { to } 15 \text { Corrugated rail }\end{array}$ \\
\hline Welded Rail & 0 & Eliminates joints & 0 \\
\hline Rail joint maintenance & 0 & 2 to 5 (joints) & 0 \\
\hline Rail (or wheel) lubrication & Reduces or eliminates & 0 & 0 \\
\hline Resilient or damped rail & Unpredictable & $\begin{array}{c}0 \text { to } 2 \text { At grade } \\
4 \text { to } 6 \text { Steel elevated }\end{array}$ & $\begin{array}{c}0 \text { to } 2 \text { At grade } \\
4 \text { to } 6 \text { Steel elevated }\end{array}$ \\
\hline Resilient rail fasteners & 0 & 3 to 6 Steel elevated & 3 to 6 Steel elevated \\
\hline $\begin{array}{l}\text { Wayside barriers } \\
\text { (3-6.5 ft high) }\end{array}$ & 5 to 15 & 5 to 15 & 5 to 15 \\
\hline Vehicle skirts & 0 to 3 & 0 to 3 & 0 to 3 \\
\hline $\begin{array}{c}\text { Composition (vs. cast iron) } \\
\text { tread brakes }\end{array}$ & 0 & Prevent small flats & 5 to 7 \\
\hline Vehicle speed reduction & Reduces likelihood of squeal & 6 to 12 per halving of speed & 6 to 12 per halving of speed \\
\hline
\end{tabular}




\subsubsection{Correction and Maintenance of Rail Profile}

Another preferred option is maintaining and correcting the rail profile, being effective in the frequency range up to $50 \mathrm{~Hz}$, reaching reductions close to $10 \mathrm{~dB}$. With this in mind, railway grinding has been in use for several years now, with a broad range of specific purpose works such as grinding of switches and crossings and removal of defects and specific sites harder to reach by other mitigation methods. The process of grinding a rail produces a much more consistent profile, transversely and also longitudinally, and can remove shallower depths of metal than most other measures, such as milling and planning, which increases rail life as illustrated in Figure 4. Along with that, acoustic grinding stands as a much better developed method for this target. For this reason, rail acoustic grinders are the most used equipment for corrective maintenance of railways [2,3].

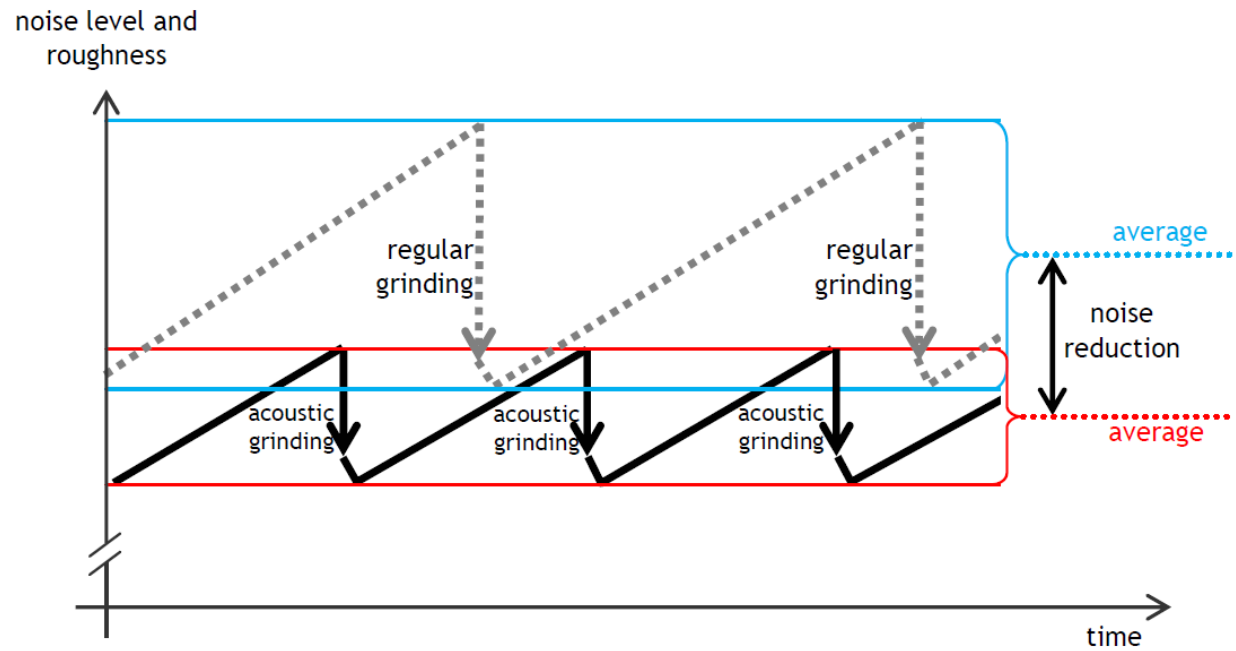

Figure 4. Effects of maintenance grinding and acoustic grinding along time [2].

Alongside that approach, the usage of a ballast mat is beneficial too when thinking about it as a derivative approach of maintaining rail profile measures. Through this method, soil vibration levels are reduced substantially by a scale of 2 to $5 \mathrm{~dB}$ in the range of 40 to $200 \mathrm{~Hz}$ frequencies. When used in conjunction with other measures such as track resilience improvements, rail profile correction can result in valid rail and soil vibration reduction by 7.5 for rail and $10 \mathrm{~dB}$ for soil $[16,17]$.

\subsubsection{Jointless Switches}

More specifically, the gaps that are part of the turnouts can be described physically by its width, the step height (vertical level difference on either side of the gap) and the dip angle, which is caused by the rail edge that is pushed down by the wheel [16]. Further investigation already showed that the noise is mostly increased by variations on the depth and the dip angle of the gaps and the velocity of the train relates to the sound emitted by a single joint with a function of $20 \log \mathrm{V}$, which means that a train running speed $(\mathrm{V})$ at $80 \mathrm{~km} / \mathrm{h}$ is emitting about $6 \mathrm{~dB}$ more than one at $40 \mathrm{~km} / \mathrm{h}$ [18]. Thus, an efficient measure to mitigate the impact sound, alongside the ones already highlighted, is to develop a better calculated design for these components of the special trackwork.

Furthermore, using joints that smooth the interaction of the wheel changing from one rail to another has already been proven in order to reduce the impact to infrastructure, especially in turnouts as shown in Figure 5. Hence, recent designs of special trackworks have adopted bonded joints or insulated joints with bonds and bolts [8]. Finally, for rattling noises, jointless switches are state-of-the-art nowadays, reducing the noise emission by $2-4 \mathrm{~dB}$ [9]. This is applied especially for railways in which speeds over $40 \mathrm{~km} / \mathrm{h}$ are expected to be achieved. In these cases, the turnout length is designed to be much longer to allow higher velocity. 


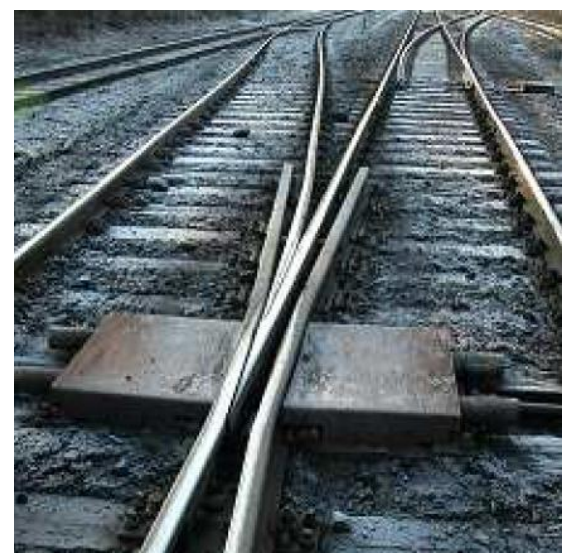

(a)

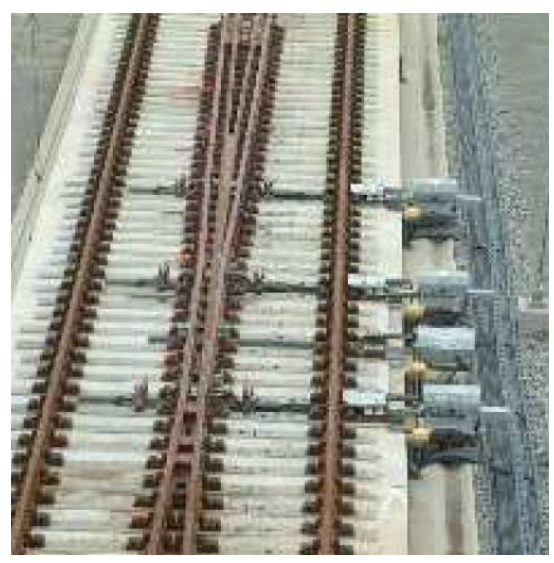

(b)

Figure 5. Examples of switches with swingnose crossing and jointless switches [2].

\subsubsection{Friction Modifiers}

Since switches are also composed of small radius curves, which affect operating speeds and may vary from 90 to $2000 \mathrm{~m}$, the high pitch noises that occur in these elements have the same origin as the ones in general curves. However, it is important to be clear which type of noise is more evident, as there can be flanging noises or curve squeal noises over closure rails of a switch as both have different solutions depending upon their intensity and economic feasibility. The wheel squeal noise is related to a lateral stick-slip behavior between the wheel and the rail and generates a very high tonal noise associated with wheel frequencies. As for the flanging noise, it can be described as a non-tonal that sounds more like high level noises of the consonants " $\mathrm{f}$ " and " $\mathrm{s}$ ".

These types of noises can be resolved by applying friction modifiers or lubrication, although the friction coefficient should not reach low values as it would provoke an adhesion problem for traction and even braking, the last being very critical also in special trackworks. Therefore, friction modifiers are designed to control friction rather than reducing it to zero, and are applied on top of the rail, as this is the most critical part of the wheel/rail contact, and its use aids the reduction of wear and corrugation in curves alongside reducing squeal noise and flanging noise, when applied at the wheel flange and against the gauge corner of the rail or at the check rail. Table 1 shows the typical outcome.

As for practical feasibility, track mounted systems for gauge-face lubrication (see Figure 6) is state-of-the-art machinery nowadays, composed of wiping bars, drains and water spraying. In this procedure, the modifier is applied on the top of the head of the inner rail, and, in addition, when it suits the track maintainer, between the wheel flange and gauge corner of the outer rail, as it aids to reduce flanging noise [19]. Aside from this, vehicle mounted systems also exist (such as the jetting method), but represent a very costly measure yet.

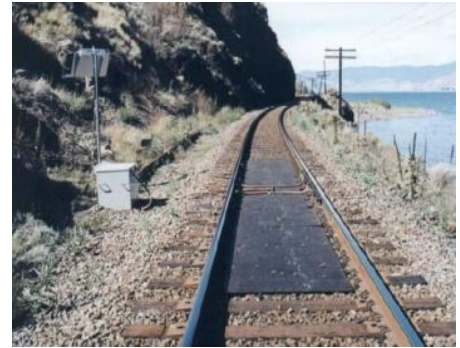

(a)

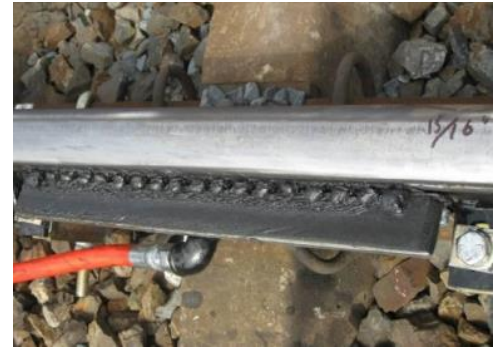

(b)

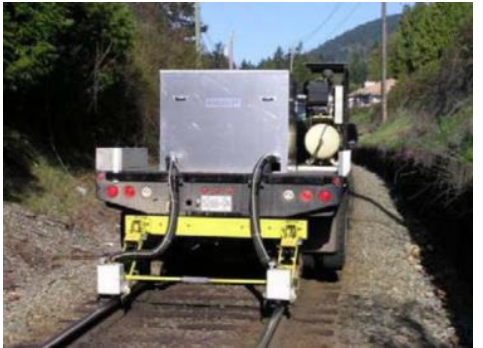

(c)

Figure 6. Example of rail based and vehicle based lubrication [20]. 
Despite having many benefits from using friction modifiers in railways, precautions should be made since there are a variety of defects that correlate to their poor usage: wheel flats and loss of traction at curves due to grease on top of the rail, variation of properties of lubricants such as viscosity and its effectiveness due to temperature and aging, increase in wear on the wheel and rails by using water based lubricants that can also freeze or evaporate on harsh weather conditions, progressive growth of rail squats due to incompressible fluid in crack tips, etc. [8]. Anyhow, the mitigation of squeal and flanging noise in switches can help reduce the amount of sound emitted in this facilities by 5 to $20 \mathrm{~dB}[20]$.

Aside from this, even more important is the cost that this measure implies on the railway operation. Having no use of lubrication along the life cycle of the track strongly affects the wheel life as can be seen in the previous study [20]. Furthermore, the use of vehicle lubrication stands out as the most efficient method for expanding wheel life in railway maintenance.

\subsubsection{Other Methods}

It is worth pointing out that an ideal geometry on turnouts, especially of the crossing nose, helps to avoid loss of contact between the wheels and the rail at these elements, hence the effects of impact forces generated due to the dipped-like trajectory are generally lower than is regular conditions of degraded track or track geometry [16]. Furthermore, noise barriers are considered to help establish noise control everywhere as they are low-investment infrastructure with a maximum height of $2 \mathrm{~m}$ above rail head. In total, 280,000 $\mathrm{km}$ of the European network is fringed by these barriers, which culminates in an annual cost of 70,000 euros per $\mathrm{km}$ for noise barriers with a total annual cost for Europe of 20 billion euros, which is called the equivalent barrier cost [21].

There are two main alternatives for noise barriers. The normal ones are built at distances of about $4.5 \mathrm{~m}$ from the track axis, being as high as $4 \mathrm{~m}$ above the railhead. The second type, named low-close barriers, are usually at $1.7 \mathrm{~m}$ from the axis and with heights reaching only $1 \mathrm{~m}$.

A summary of most wheel/rail treatments for noise control, with their expected outcomes in industry use over the three types of noises exposed here, can be seen at the end of this section.

\subsection{Methodology}

In order to properly access the most feasible options in practical and economic terms, a life cycle costing (LCC) analysis will be followed based upon the different aspects of each method and their impacts. Railways are already known as highly costly to construct and operate, but maintenance also plays a very important part of its life cycle as it helps stretch the durability of its components. Because of all of these aspects of railways, it is vital that maintenance walks alongside noise control measures and each supports the other. Thus, secondary improvements and solutions such as noise abatement measures do not work as threats to the economic viability of railways.

According to LCC theory, the decision of opting for one option over another should be made in a way that results in the lowest total costs over the life span of a determinate process, which in this case is the whole of the railway system [22]. Railways already operate with restricted budgets even without having to consider noise control, so following an action plan that proves to be an efficient method to calculate the total network costs of implementing such measures with different consequences is obviously very important [23].

Maintenance of the wheel/rail interface has two fundamental aspects: the control of friction and control of wheel and rail profile, which thankfully correlates with the approach for abating sound emission as already seen in Section 4. Even though the stake holders would enjoy having a railway in a perfect state, the key motivation for maintaining either rail and freight is economics. Thus, it is more about how economically the railway operates than the state of it, although some levels were already mentioned as being necessary to reach [24].

In recent studies [22-24], the life cycle cost analysis shows that the overall costs of noise control measures at source are lower than the ones of noise barriers or façade insulation only. These barrier 
costs evaluated (pointed as the equivalent barrier cost) can be compared to the total annual cost of track maintenance and renewal, which are 70 billion euros, as around $30 \%$ of this.

\section{Results and Discussion}

\subsection{Assumptions}

Based on industry reports, assumptions from the railway industry have been addressed. The benefits acquired for each method can be seen below, as well as the cost assumptions for the whole life cycle evaluation, in Table 3. The discount rate considered in all projections is of $5 \%$ over 50 years of cash flows:

- $\quad$ Benefit for Track and Rail based Lubrication: $£ 3500.00$;

- Benefit for Resilient Wheels: $£ 3000.00$.

The values were assumed taking into account that routine maintenance is often undertaken to a fixed cycle whose period is previously defined by rail operators and maintainers and determined by terms of the passage of traffic.

Table 3. Cost assumptions (in $£$ ) for life cycle analysis regarding squeal and impact noise abatement measures [25-30].

\begin{tabular}{cccccccc}
\hline Mitigation Measure & First Cost & Control Case & Replacement & Climate Cost & \multicolumn{2}{c}{$\begin{array}{c}\text { Control Case for } \\
\text { Climate Cost }\end{array}$} \\
\hline Track Based Lubrication & 20,000 & 4000 & yearly & 13 years & 20,000 & 5000 & 4 times a year \\
Conventional Barriers & 850,000 & 850,000 & 25 years & Yes & 850,000 & 850,000 & 15 years \\
Jointless Switches & 450,000 & 450,000 & 25 years & 10 years & 450,000 & 450,000 & 8 years \\
Low-close Barriers & 650,000 & 650,000 & 20 years & Yes & 650,000 & 650,000 & 10 years \\
Rail Damping & 174,000 & 8000 & yearly & 13 years & 174,000 & 11,000 & 4 times a year \\
Resilient Wheels & 30,000 & 1000 & yearly & 30 years & 30,000 & 1200 & 12 times a year \\
Vehicle Based Lubrication & 30,000 & 2800 & yearly & 15 years & 16,000 & 4000 & 4 times a year \\
\hline
\end{tabular}

\subsection{Friction Modifiers}

In order to compare more efficiently the viability of using lubricants in railways special trackworks, the two categories of friction modifiers mentioned before were compared using the assumptions exposed above (see Figure 7).

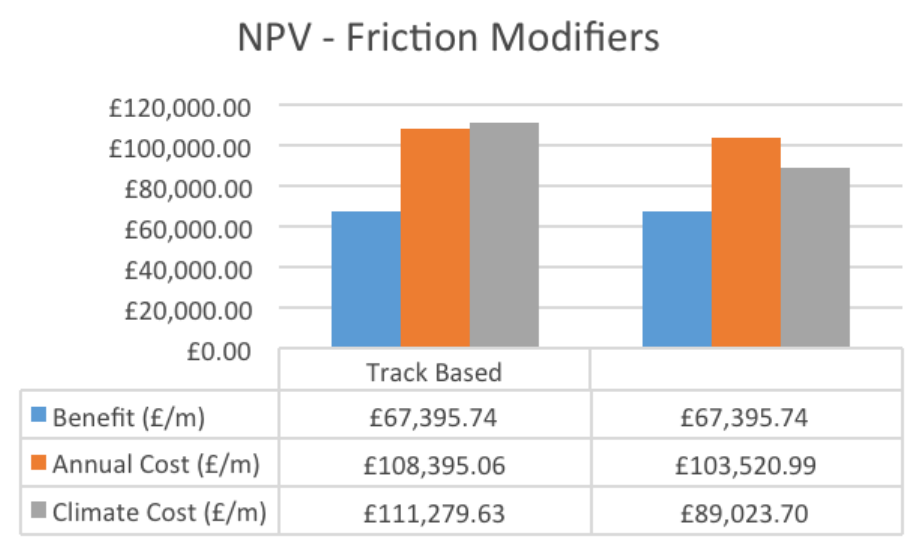

Figure 7. Net present values for two categories of friction modifiers.

Based on Figure 4, the outcome of this analysis exhibits that even though vehicle based lubricants are considered a state-of-the-art method, with higher initial costs ( $£ 30,000$ compared to $£ 20,000$ ), the benefits of choosing this measure stand out by taking into consideration the long-term benefits. The maintenance of this method is also cheaper, but the replacement period is wider. 


\subsection{Noise Barriers}

In this evaluation, two types of the same methodology were compared regarding their cost life cycles. The low-close noise barriers are already a good alternative theoretically as they can be installed nearer the track and in most locations with similar results to noise abatement of conventional ones (see Figure 8).

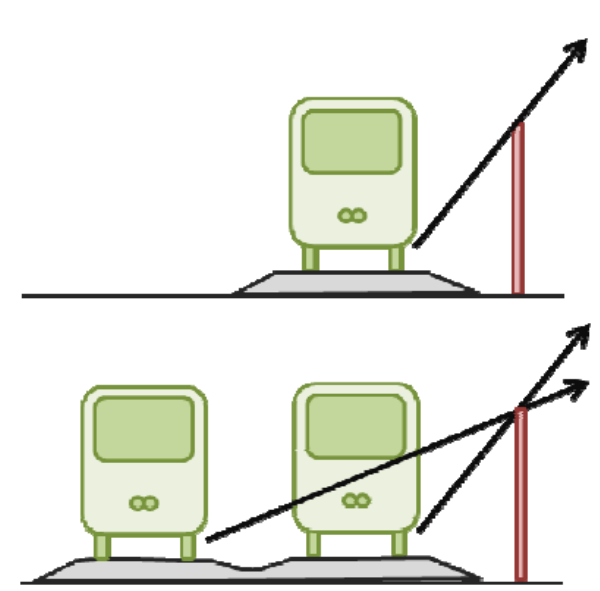

(a)

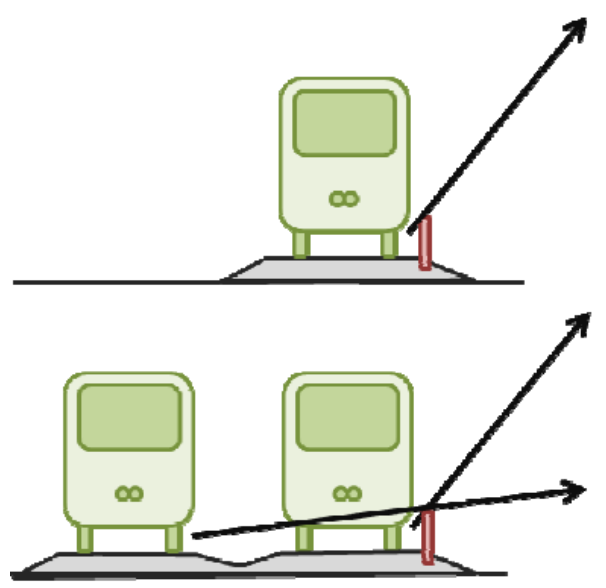

(b)

Figure 8. Schematics of conventional (a) and low-close noise (b) barriers [2].

The results shown in Figure 9 reveal that the low close noise barriers are a better option across a long period of analysis. The high investment costs for the conventional barriers block the viability of using them for the entire extensions of track, but the conditions of which the properties of each type works better should be considered. In twin tracks, low close barriers are not as effective, and the use of conventional ones should be studied. Since special trackworks are complex systems, the feasibility of having to opt to one over another might be a downside to this method.

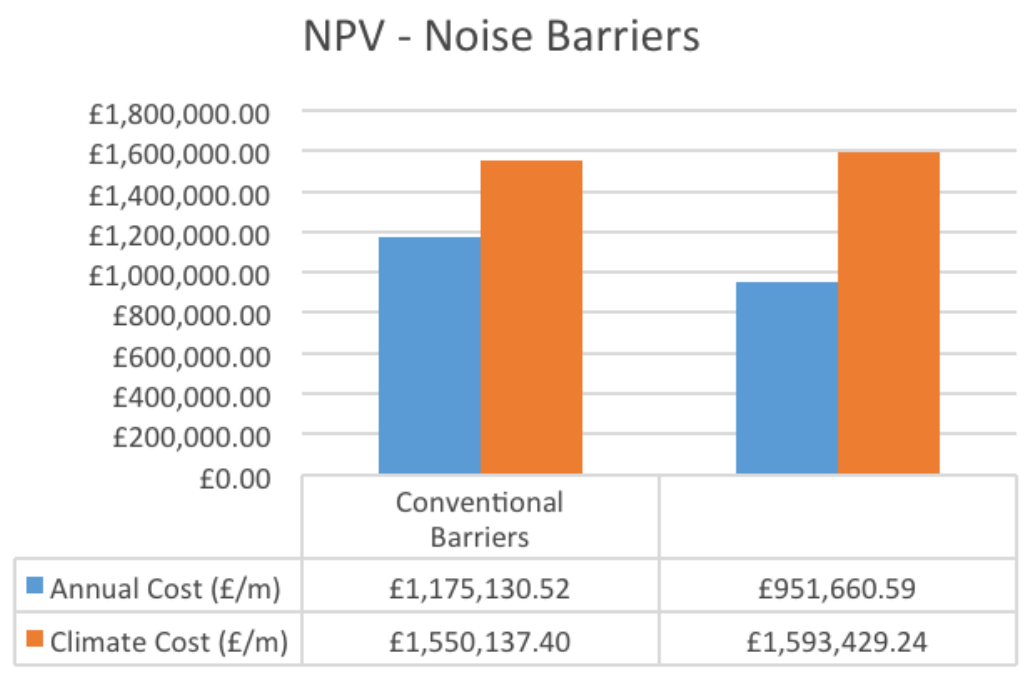

Figure 9. Net present values for two categories of noise barriers.

\subsection{Jointless Switches}

This is the most specific measure for impact noise and vibration, hence there should be special considerations regarding its feasibility as the reduction of noise and vibration acquired by this method 
is substantial (see Figure 10). The final costs seen in Figure 9 show that this method, as it is applied by a state-of-the-art technology, is the most expensive amongst the other ones, and, therefore, should be analyzed as an alternative only when it is strictly necessary to properly abate the impact vibration due to the special trackwork components.

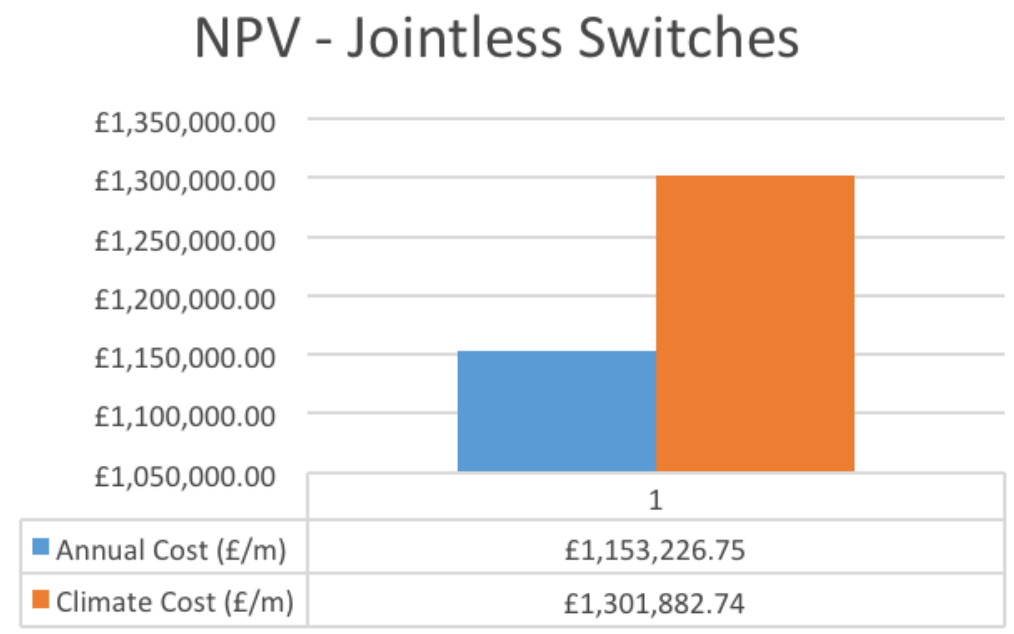

Figure 10. Net present values for jointless switches.

\subsection{Rail Damping}

As rail damping can be used as a complement to other methods, with reasonable results, it is important to know whether this addition to railway maintenance methodology is feasible economically speaking [21,25-30].

The costs to apply this technology are not as high as jointless switches, hence it can be used in conjunction with more basic options such as resilient wheels and friction modifiers. The outcome of this relation is a good reduction of both impact and squeal noises (see Figure 11).

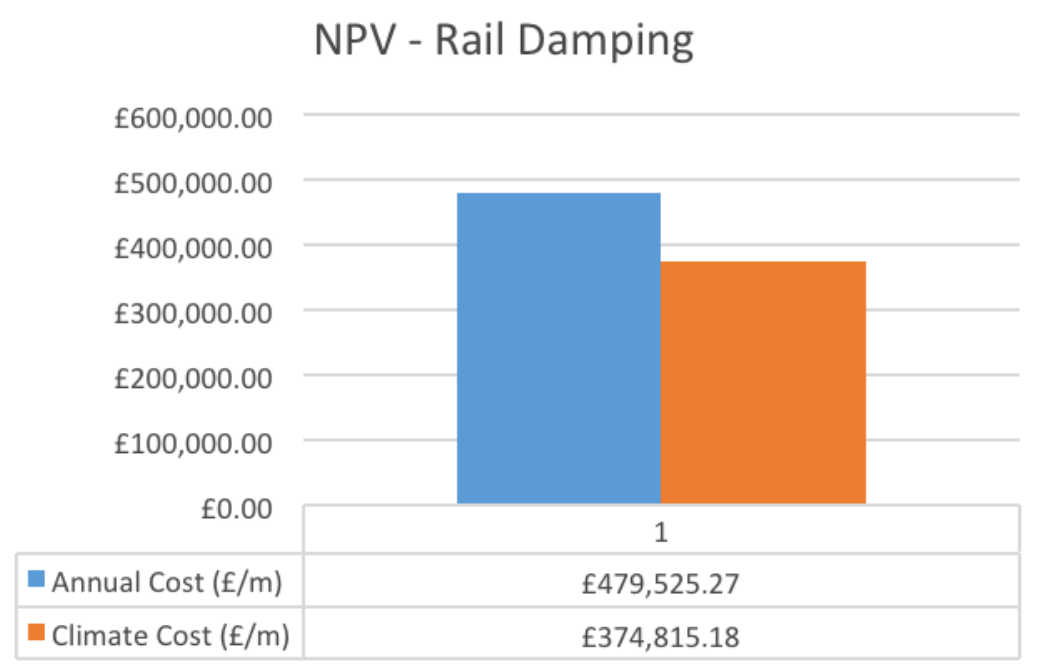

Figure 11. Net present values for rail damping.

\subsection{Resilient Wheel}

Finally, resilient wheels are already considered an efficient and cheap method for reducing railway noise emission, as seen by previous studies [28-33], and the results agree with previous findings. This being the case, a good option is to complement other methods with this, since wheels 
are not usually a responsibility of the railway contractor, being delegated by the operators of the trains (see Figure 12).

\section{NPV - Resilient Wheels}

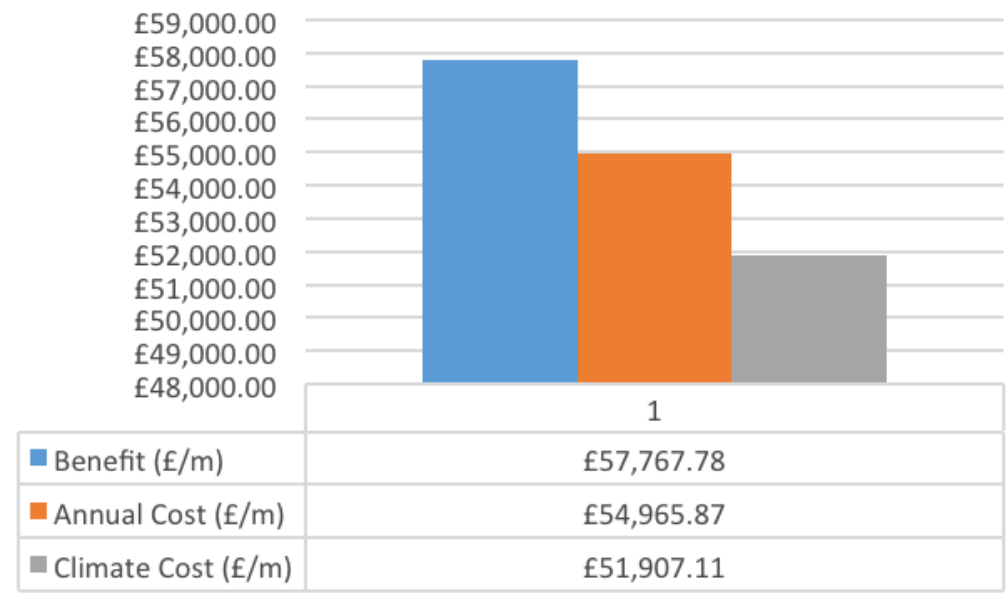

Figure 12. Net present values for resilient wheels.

\section{Conclusions}

The maintenance of railway track consists of a significant area of interest for the industry due to its high cost values and the outcomes expected by its proper application [29]. More specifically, the noise and vibration reduction methods are a growing pursuit for solutions for companies since their effects on the communities are becoming more and more noticed.

As a general perspective for noise generation and abatement in turnouts and crossings, the methodologies that stand out as better solutions are friction modifiers in conjunction with resilient wheels and rail damping systems. This combination will express a condition in which squeal noise is nearly reduced to 0 and impact noise values will reduce by about $10 \mathrm{~dB}$.

For the impact noise, the most expensive option is using jointless switches with proven full reduction of impact noises or using damping and resilient wheels that can still reduce the noise on a lower scale. Thus, the option depends on how critical the condition of the area is and the complaints of the community and rail stakeholders.

Finally, for curve noises (squeal and flanging noises), the best solution is the low close noise barriers, although this is also the most expensive one and therefore should only be used in areas where they are strictly needed, while leaving the other evaluated parts of the track available for other methods to be applied such as lubricants and damping.

In conclusion, the use of any mitigation measure discussed here is of vital importance for the preparation of a successful plan of action that seeks to reduce or abate noise generation in railway systems, but the maintenance of their elements and components is even more essential so the condition of each one of them does not present itself in a deteriorated state [34-36].

Acknowledgments: The information provided or obtained online contained sufficient data for a high quality of work to be developed; hence, the authors are grateful for the material that made possible the development of a study that evaluated the methodologies currently used by the industry partners. The first author would like to thank Brazil's Sciences without Borders for his scholarship at the University of Birmingham. The authors are sincerely grateful to the European Commission for the financial sponsorship of the H2020-RISE Project No. 691135 "RISEN: Rail Infrastructure Systems Engineering Network", which enables a global research network that tackles the grand challenge of railway infrastructure resilience and advanced sensing in extreme environments (www.risen2rail.eu). Technical assistance from Tomasz Lewandrowski is also highly appreciated.

Author Contributions: Rodrigo Tavares de Freitas and Sakdirat Kaewunruen conceived and designed the parameters; Rodrigo Tavares de Freitas and Sakdirat Kaewunruen performed the analyses; Rodrigo Tavares de 
Freitas and Sakdirat Kaewunruen analyzed the data and contributed reagents/materials/analysis tools; both also wrote the paper.

Conflicts of Interest: The authors declare no conflict of interest. The founding sponsors had no role in the design of the study; in the collection, analyses, or interpretation of data; in the writing of the manuscript, and in the decision to publish the results.

\section{References}

1. Brons, M.; Nijkamp, P.; Pels, E.; Rietveld, P. Railroad noise: Economic valuation and policy. Transp. Res. Part D Transp. Environ. 2003, 8, 169-184. [CrossRef]

2. International Union of Railways (UIC). Railway Noise Technical Measures Catalogue; UIC: Paris, France, 2013.

3. Licitra, G.; Fredianelli, L.; Petri, D.; Vigotti, M.A. Annoyance evaluation due to overall railway noise and vibration in Pisa urban areas. Sci. Total Environ. 2016, 568, 1315-1325. [CrossRef] [PubMed]

4. Bunn, F.; Henrique, P.; Zannin, T. Assessment of railway noise in an urban setting. Appl. Acoust. 2016, 104, 16-23. [CrossRef]

5. Kephalopoulos, S.; Paviotti, M.; Anfosso-Lédée, F. Common Noise Assessment Methods in Europe (CNOSSOS-EU); Publications Office of the European Union: Luxembourg City, Luxembourg, 2012; p. 180.

6. Kassa, E.; Nielsen, J. Dynamic train-turnout interaction in an extended frequency range using a detailed model of track dynamics. J. Sound Vib. 2009, 320, 893-914. [CrossRef]

7. Oertli, J. Developing noise control strategies for entire railway networks. J. Sound Vib. 2006, 293, $1086-1090$. [CrossRef]

8. Kurzweil, L. Wheel/rail noise-Means for control. J. Sound Vib. 1983, 87, 197-220. [CrossRef]

9. Oertli, J. The STAIRRS project, work package 1: A cost-effectiveness analysis of railway noise reduction on a European scale. J. Sound Vib. 2003, 267, 431-437. [CrossRef]

10. Vér, I.L.; Ventres, C.S.; Myles, M.M. Wheel/rail noise-Part III: Impact noise generation by wheel and rail discontinuities. J. Sound Vib. 1976, 46, 395-417. [CrossRef]

11. Kouroussis, G.; Connolly, D.P.; Alexandrou, G.; Vogiatzis, K. The effect of railway local irregularities on ground vibration. Transp. Res. Part D Transp. Environ. 2015, 39, 17-30. [CrossRef]

12. Kouroussis, G.; Connolly, D.P.; Alexandrou, G.; Vogiatzis, K. Railway ground vibrations induced by wheel and rail singular defects. Veh. Syst. Dyn. 2015, 53, 1500-1519. [CrossRef]

13. Nielsen, J.C.O.; Mirza, A.; Cervello, S.; Huber, P.; Müller, R.; Nelain, B.; Ruest, P. Reducing train-induced ground-borne vibration by vehicle design and maintenance. Int. J. Rail Transp. 2015, 3, 17-39. [CrossRef]

14. Connolly, D.P.; Marecki, G.P.; Kouroussis, G.; Woodward, P.K. The growth of railway ground vibration problems-A review. Sci. Total Environ. 2016, 568, 1276-1282. [CrossRef] [PubMed]

15. Kalivoda, M.; Danneskiold-Samsøe, U.; Krüger, F.; Barsikow, B. EURailNoise: A study of European priorities and strategies for railway noise abatement. J. Sound Vib. 2003, 267, 387-396. [CrossRef]

16. Bruni, S.; Anastasopoulos, I.; Alfi, S.; Van Leuven, A.; Gazetas, G. Effects of train impacts on urban turnouts: Modelling and validation through measurements. J. Sound Vib. 2009, 324, 666-689. [CrossRef]

17. Thompson, D. Railway Noise and Vibration-Mechanisms, Modelling and Means of Control; Elsevier: Oxford, UK, 2009.

18. Wu, T.X.; Thompson, D.J. On the Impact Noise Generation due to a Wheel Passing over Rail Joints. J. Sound Vib. 2003, 267, 485-496. [CrossRef]

19. Degen, K.G.; Asmussen, B. Innovative Masnahmen zum Larm- und Erschutterungsschutz am Fahrweg; DB Netz AG: Frankfurt, Germany, 2012.

20. Buhler, S.; Thallemer, B. How to avoid squeal noise on railways state of the art and practical experience. In Noise and Vibration Mitigation for Rail Transportation Systems; Springer: Berlin, Germany, 2007.

21. De Vos, P. How the money machine may help to reduce railway noise in Europe. J. Sound Vib. 2003, 267, 439-445. [CrossRef]

22. Brandes, K. Life-Cycle-Cost Analysis and Design of Civil Infrastructure Systems. Stahlbau 2003, 72, 534. [CrossRef]

23. Oertli, J. Cost-benefit analysis in railway noise control. J. Sound Vib. 2000, 231, 505-509. [CrossRef]

24. Union Internationale des Chemins de Fer. The Real Cost of Railway Noise Mitigation a Risk Assessment; Union Internationale des Chemins de Fer: Paris, France, 2013.

25. García Márquez, F.P.; Lewis, R.W.; Tobias, A.M.; Roberts, C. Life cycle costs for railway condition monitoring. Transp. Res. Part E Logist. Transp. Rev. 2008, 44, 1175-1187. [CrossRef] 
26. Australian Government's Cooperative Research Centres Programme (CRC). Annual Report-Rail Curve Lubrication Best Practice for AUSTRALIAN Heavy Haul Lines; SRC: Brisbane, Australia, 2011.

27. Parker, A.; Weber, C. Rail Dampers-The First Australian Field Trial; Heggies Pty Ltd.: Sydney, Australia, 2010.

28. Setsobhonkul, S.; Kaewunruen, S. Life cycle analysis of railway noise and vibration mitigation methodologies with respect to curve squeal noises. In Proceedings of the 45th International Congress and Exposition on Noise Control Engineering INTER-NOISE, Humburg, Germany, 21-24 August 2016; pp. 1-10.

29. Railway Induced Vibration Abatement Solutions Collaborative Project (RIVAS). Definition of Wheel Maintenance Measures for Reducing Ground Vibration; RIVAS: Brussels, Belgium, 2013.

30. Tuler, M.V.; Kaewunruen, S. Life cycle analysis of mitigation methodologies for railway rolling noise and groundbourne vibration. J. Environ. Manag. 2016, in press.

31. Prescott, D.; Andrews, J. Modelling Maintenance in Railway Infrastructure Management. In Proceedings of the 2013 Annual Reliability and Maintainability Symposium (RAMS), Orlando, FL, USA, 28-31 January 2013.

32. Talotte, C.; Gautier, P.-E.; Thompson, D.J.; Hanson, C. Identification, modelling and reduction potential of railway noise sources: A critical survey. J. Sound Vib. 2003, 267, 447-468. [CrossRef]

33. Grassie, S. Rail corrugation: Advances in measurement, understanding and treatment. Wear 2005, 258, 1224-1234. [CrossRef]

34. Lewis, R. Maintenance of the wheel-rail interface. In Wheel-Rail Interface Handbook, 1st ed.; Woodhead Publishing: Cambridge, UK, 2009.

35. Kaewunruen, S.; Remennikov, A.M. Current state of practice in railway track vibration isolation: An Australian overview. Aust. J. Civ. Eng. 2016, 14, 63-71. [CrossRef]

36. Remennikov, A.M.; Kaewunruen, S. A review of loading conditions for railway track structures due to train and track vertical interaction. Struct. Control Health Monit. 2008, 15, 207-234. [CrossRef]

(C) 2016 by the authors; licensee MDPI, Basel, Switzerland. This article is an open access article distributed under the terms and conditions of the Creative Commons Attribution (CC-BY) license (http://creativecommons.org/licenses/by/4.0/). 